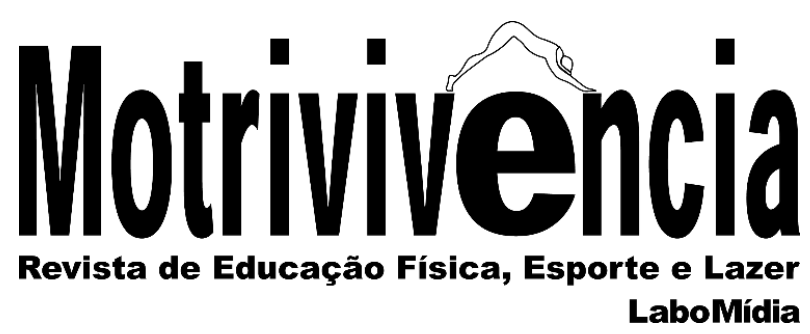

\title{
A prática pedagógica da Educação Física na escola de tempo integral num olhar multirreferencial
}

\section{RESUMO}

O presente artigo é um ensaio teórico que objetiva apresentar uma reflexão sobre a prática pedagógica da Educação Física na escola de tempo integral a partir do fundamento epistemológico da multirreferencialidade. A multirreferencialidade é uma perspectiva epistemológica que nega a existência do conhecimento de um ponto de vista purista e monológico, compreendendo os fenômenos em sua complexidade. A Educação Física, enquanto prática pedagógica, por muito tempo se justificou pelo referencial da aptidão física e do rendimento com o fim da formação esportiva, privilegiando uma formação voltada para a técnica do movimento padronizado, ficando restrita a referenciais únicos. É como espaço de relações plurais que concebemos a escola de tempo integral, e a Educação Física como parte desse contexto deve desenvolver uma prática pedagógica que perspective uma leitura plural a consciência corporal dos sujeitos implicados, fazendo-os compreender sua participação na sociedade como agentes, atores e autores que criam sentidos.

PALAVRAS-CHAVE: Educação física; Escola de tempo integral; Prática pedagógica;

Multirreferencialidade
Mackson Luiz Fernandes da Costa

Doutor em Educação Instituto Federal do Rio Grande do Norte -

IFRN

João Câmara, Rio Grande Norte, Brasil macksonluiz@gmail.com

근 https://orcid.org/0000-0001-7533-971X

José Pereira de Melo Pós doutor em Educação

Universidade Federal do Rio Grande do Norte - UFRN

Departamento de Educação Física, Natal, Rio Grande Norte, Brasil jose.pereira.melo@uol.com.br

(ㄴ) https://orcid.org/0000-0002-1968-4110 
The pedagogical practice of Physical Education in the integral time school in a multireferential view

\begin{abstract}
This article is a theoretical essay that aims to present a reflection on the pedagogical practice of Physical Education in full time school based on the epistemological foundation of multireferentiality. Multireferentiality is an epistemological perspective that denies the existence of knowledge from a purist and monological point of view, understanding the phenomena in its complexity. Physical Education, as a pedagogical practice, was for a long time justified by the reference of physical fitness and performance to the end of sports training, privileging a training focused on the technique of standardized movement, being restricted to unique referential. It is as a space of plural relations that we conceive the full-time school, and Physical Education as part of this context must develop a pedagogical practice that perspectives a plural reading the corporal consciousness of the subjects involved, making them understand their participation in society as agents, actors and authors who create senses.
\end{abstract}

KEYWORDS: Physical education; School of integral time; Pedagogical practice; Multireferentiality

\title{
La práctica pedagógica de la Educación Física en la escuela de tiempo integral en una mirada multireferencial
}

\section{RESUMEN}

El presente artículo es un ensayo teórico que objetiva presentar una reflexión sobre la práctica pedagógica de la Educación Física en la escuela de tiempo integral a partir del fundamento epistemológico de la multirreferencialidad. La multirreferencialidad es una perspectiva epistemológica que niega la existencia del conocimiento desde un punto de vista purista y monológico, comprendiendo los fenómenos en su complejidad. La Educación Física, como práctica pedagógica, por mucho tiempo se justificó por el referencial de la aptitud física y del rendimiento con el fin de la formación deportiva, privilegiando una formación orientada a la técnica del movimiento estandarizado, quedando restringida a referenciales únicos. Es como espacio de relaciones plurales que concebimos la escuela de tiempo completo, y la Educación Física como parte de ese contexto debe desarrollar una práctica pedagógica que perspectiva una lectura plural la conciencia corporal de los sujetos implicados, haciéndolos comprender su participación en la sociedad como agentes, actores y autores que crean sentidos.

PALABRAS-CLAVE: Educación física; Escuela de tiempo completo; Práctica pedagógica; Multireferencialidad 


\section{INTRODUÇÃO}

No Brasil, a incerteza no campo educacional em torno da estruturação de uma escola de tempo integral tem ganhado destaque na última década. Um dos grandes desafios é não reproduzir um modelo de escola que apenas aumente o tempo de permanência do aluno, mas aproveitar a oportunidade para desenvolver uma escola que considere todos os saberes que envolvem a vida dos educandos, propondo um currículo que considere a educação escolar e não escolar que provoque mudanças no uso do tempo e do espaço da escola.

As inquietações com relação à escola de tempo integral surgem ao deparar-se com a realidade de um sistema educacional que visualiza a ampliação do tempo escolar como uma possibilidade de melhor assistência educacional para as crianças, adolescentes e jovens do Brasil. Todavia, ainda se encontra, na atual realidade da escola, uma dificuldade de materializar e efetivar práticas pedagógicas e políticas para a escola de tempo regular. Para pensar a escola de tempo integral não se pode olhar de maneira fragmentada, mas considerar todas as referências que a constitui, articulando o fazer pedagógica ao currículo e ao projeto pedagógico da escola, servindo de orientação para todos os atores da escola, sendo assim possível começar a pensar em qualidade da educação escolarizada com a ampliação do tempo de permanência do aluno.

É nesse contexto que visualizamos a necessidade de retomar uma reflexão sobre a Educação Física enquanto um componente curricular pedagogicamente organizado para atender a realidade de uma escola de tempo integral que considere o sujeito integralidade.

A Educação Física como prática pedagógica tem sido concebida a partir de diversas perspectivas durante a história, atribuindo sentidos ao seu papel no processo formativo, tanto em espaços formais como em espaços informais. Dentre muitas compreensões, entendemos que a Educação Física no contexto escolar objetiva inserir o educando na cultura de movimento como um conhecimento pedagógico que lhe permite criar autonomia e criticidade no processo de formação concernente ao uso do corpo nas práticas corporais. Para isso, o professor deve estar ancorado em uma rede de saberes que compreenda as pessoas em sua totalidade, pois as compreendem enquanto sujeitos corporais que interagem com o outro e o mundo.

Assim como os demais componentes curriculares, a Educação Física deve reconhecer o seu papel nessa realidade da escola de tempo integral, apresentando-se como fundamental para justificar a ampliação do tempo no espaço escolar, com o intuito de ofertar uma formação integral.

Diante do complexo que envolve a Educação Física e a escola de tempo integral, devemos buscar olhar para os fenômenos em sua totalidade. Isso tem sido uma das dificuldades para o atual 
contexto, pois ao mesmo tempo em que vive uma globalização que requer hibridização de saberes, ainda tem a especialização como meta formativa, principalmente pelo processo de racionalização e objetivação.

Neste sentido, este artigo se caracteriza como um ensaio teórico que objetiva apresentar uma reflexão sobre a prática pedagógica da Educação Física na escola de tempo integral a partir do fundamento epistemológico da multirreferencialidade.

\section{UMA EDUCAÇÃO FÍSICA MULTIRREFERENCIAL}

A multirreferencialidade, que tem como principal pensador Jacques Ardoino (1998), é uma perspectiva epistemológica do conhecimento que nega a existência do conhecimento de um ponto de vista purista e monológico, compreendendo os fenômenos em sua complexidade, relacionandoos a dimensão do imaginário.

Para Ardoino (1998), a multirreferencialidade assume o pensamento da complexidade, mas na perspectiva de uma "radical pluralização", em que a busca de articulação entre o que é heterógeno sempre está aberto às referências, não cabendo pensar em uma multidimensionalidade que converge. Por isso o autor coloca o termo "holístico" como uma substituição para a complexidade que envolve os fenômenos humanos, pois:

Seria preciso, em seguida, concordar que a representação sistêmica da complexidade também não é inteiramente suficiente para dar conta de certos aspectos característicos das práticas e das situações sociais, especialmente a consistência particular de uma temporalidade-duração mais histórica (ARDOINO, 1998, p. 26).

Os fenômenos são suscetíveis a diversas análises que podem partir de referências diferentes, fazendo-se necessária uma leitura plural para o reconhecimento dos múltiplos vieses nos quais eles podem estar situados e criar um entendimento próprio. Nesse sentido, a visão em torno dos fenômenos sociais deve partir dos diversos olhares dos que os produzem, buscando compreender os contextos dessas produções. Ou seja, tem que considerar o indivíduo com seu poder criador e significações, as diversas sociedades em suas particularidades e os encontros entre esses indivíduos e sociedades, como nos deparamos na configuração do mundo globalizado, adornado de significações em torno dos diversos saberes produzidos.

Ancorar-se na multirreferencialidade não é produzir algo novo, mas voltar o olhar com uma leitura plural, reconhecendo a complexidade dos fenômenos e o que está atrelado a eles em sua 
totalidade. Soares (2006), ao escrever o prefácio do livro Educação do corpo na escola brasileira, apresenta uma análise que encaminha para a perspectiva multirreferencial, ao dizer que, na educação do corpo na escola, aproximar-se de uma compreensão de que ela é intermediada por saberes e práticas diversas, perpassando todas as dimensões da vida. É na materialidade dos corpos que se atesta essa diversidade e polissemia na condição de existência do humano.

É nesse contexto de múltiplos saberes e práticas na educação do corpo na escola que a Educação Física se encontra e é a partir da educação do corpo em seus vários contextos sociais repletos de sentidos e significados que o fazer pedagógico vai sendo constituído e é nesse sentido que:

Como componente curricular que trata da cultura de movimento, a Educação Física precisa garantir a vivência e a contextualização das possibilidades de expressão e comunicação dos sujeitos por meio dos jogos, esportes, ginásticas, atividades rítmicas e expressivas. Por meio do corpo e do movimento, podemos exercitar nossa condição humana, não apenas de faber, mas de ludens(MELO, 2008, p. 61).

Buscar apresentar uma prática pedagógica para a Educação Física não implica trazer uma nova visão para o que já vem sendo discutido no meio acadêmico ou o que já é desenvolvido pelos professores em sua prática cotidiana na escola, mas apresentar uma possibilidade de ampliar as perspectivas com base no que já tem materializado no "chão da escola" e no que é apresentado como inovação pedagógica como referências diversas que contribuem na tentativa de aproximar-se de uma educação integral. Para isso, uma análise multirreferencial considera todas as produções teóricas, bem como as experiências didáticas constituídas historicamente na Educação Física escolar como referência para o pensar pedagógico, seja na constituição de um currículo ou na prática cotidiana do professor.

Partimos ainda, da representação da Educação Física como um componente curricular que tem como matriz a educação do corpo, e nesse sentido, defendemos um olhar multirreferencial, pois existem inúmeras referências aos corpos e à sua educação, assim como as maneiras de pensar os corpos vivos, carnais, suas dores e prazeres, além de inúmeras maneiras de representá-los e de darlhes formas, de registrar as formas múltiplas e plurais. Isso implica o reconhecimento da Educação Física como uma prática cultural, na qual os corpos se inscrevem de "todas as regras, todas as normas e todos os valores de uma sociedade específica, por ser ele o meio de contato primário do indivíduo com o ambiente que o cerca" (DAOLIO, 2013, p. 36).

A Educação Física se adequou aos contextos educacionais em que ela esteve presente, direcionando um fazer pedagógico fundamentado em determinado contexto, nos fazendo: 
[...] reconhecer e considerar sua tradição criada ao longo de décadas. Em que pesem a profundidade de análise das recentes pesquisas e o desejo de transformação da área, as novas proposições acadêmicas não devem negar a tradição que lhe conferiu eficácia simbólica ao longo do tempo, sob risco de se distanciar do cotidiano da área (DAOLIO, 2010, p. 16).

Pensar na prática pedagógica da Educação Física é reconhecer seu aspecto plural, perpassando pela aceitação de uma construção histórica dela na escola, no reconhecimento da heterogeneidade da presença de atores sociais e da necessidade constante de transformação, mediante incompletude dos fenômenos, pois:

Neste espaço e tempo denominado escola, cotidianamente atravessado por conflitos, desencontros, afirmativos de determinados interesses e negadores de outros, mais que tratar tão somente de diferentes posicionamentos políticos e ideológicos, como temos costumeiramente interpretado, estaremos também refletindo esta hibridação de mitos, crenças, opiniões, normas, proibições e desejos-angústias de transgressão dos quais resultam valores pessoais e culturais (BARBOSA, 2012, p. 73).

Diante da indefinição de um currículo que caracterize a Educação Física no contexto da escola de tempo que vise a formação integral do sujeito, pressupõe-se a necessidade de um arcabouço teórico-prático que considere a multirreferencialidade como um eixo norteador para a prática pedagógica da Educação Física na escola, buscando desenvolver o sujeito na sua integralidade.

Hildebrandet-Stramann e Taffarel (2017) encaminham uma visão para uma Educação Física com base na multirreferencialidade, pois reconhecem que o processo do desenvolvimento humano deve atentar para aquisição de capacidades cognitivas, emocionais, sociais e de movimento. O processo de desenvolvimento de movimento da criança e jovens é um papel atribuído à Educação Física e deve considerar na prática pedagógica o movimentar-se na função instrumental, social, simbólica e sensitiva.

A função instrumental contém a capacidade de movimentar-se de maneira econômica, hábil, jeitosa e acomodável ao meio ambiente. A função social contém a capacidade de contatar outras pessoas por intermédio do movimento. A função simbólica contém a capacidade de expressar algo mediante o movimento e a função sensível contém a capacidade de explorar materiais ou a si mesmo ou de construir, com materiais, situações de movimentar-se (HILDEBRANDET-STRAMANN; TAFFAREL, 2017, p. 39).

Essa perspectiva das funções do movimentar está coerente com a perspectiva 
multirreferencial de pensar o sujeito como agente que tem uma função instrumental, o sujeito como ator atrelado à atuação consciente no contexto social e o sujeito autor como criador nas relações com o mundo. Para Barbosa (2012, p. 72):

E educação não é senão o encaminhamento no decorrer da vida desta aprendizagem contínua de se autorizar, ou, como dirá o próprio Ardoino, este exercício de se "tornar co-autor de si mesmo". Coautor, para fugir de um entendimento absoluto, pois nossa "autoria" ocorre num interior de uma cultura que é absorvida desde o nascimento, e o desafio não é outro senão este contínuo diferenciar-se, separar-se deste ou destes outros que habitam e viabilizam a aprendizagem humana.

Compreendendo a Educação no ponto de vista de promover uma aprendizagem que viabilize o processo de conscientização do sujeito como autor é que a Educação Física deve orientar sua prática pedagógica. A Educação, segundo Hildebrandet-Stramann e Taffarel (2017, p. 111),

[...] é uma parte da socialização geral, isto é, aquele setor de interações conscientes e socialmente regulamentadas, nas quais o jovem, no seu processo de desenvolvimento, é qualificado a aprender maneiras culturais de uma sociedade e prosseguir no seu desenvolvimento e nesse processo de qualificação tornar-se uma pessoa independente e responsável.

Para isso as aulas de Educação Física têm que ser um espaço democrático, em que encontramos a ação de liberdade do sujeito, dando seu papel de autor na sociedade, sendo a escola o local onde "a relação pedagógica tem na prática social o seu ponto de partida e seu ponto de chegada, resulta inevitável concluir que o critério para se aferir o grau de democratização atingido no interior das escolas deve ser buscado na prática social” (SAVIANI, 1999, p. 86).

Uma escola heterogênea tem que ver a democracia como um de seus principais fundamentos, onde "possibilita criar-se o espaço público como um lugar que pertence a todos, não a um particularmente, e onde se pode praticar a deliberação e o autoquestionamento coletivo" (SANTOS, 2012, p. 94). No espaço democrático, é muito importante desenvolver a independência dos sujeitos, principalmente dos educandos.

$\mathrm{Na}$ Educação Física, promover uma prática pedagógica que desenvolva a autonomia deve buscar uma organização didática que estimule o educando a explorar o movimento como potência de expressão do ser no mundo, o qual se expressa na corporeidade, "considerando uma releitura do seu acervo de movimentos, de forma que o jogo, a dança, a ginástica, o esporte possam expressar e comunicar a complexidade do ser humano que se movimenta" (NOBREGA, 2005, p. 83).

A relação do corpo com o espaço está atrelada ao movimentar-se, adornada por uma representação social que implica a relação com o outro e o mundo. A escola de tempo integral deve 
fazer com que os educandos se reconheçam como corpo, pois "somos mentes de sujeitos corpóreos, temporais-espaciais, de vida, não mentes, vontades abstratas incorpóreas, aespaciais, atemporais que pouco temos relacionado as possibilidades de aprender com as possibilidades do viver" (ARROYO, 2012, p. 42).

A Educação Física é importante para o processo formativo do educando, pois está voltada para uma educação do corpo, o que não é um elemento unicamente da disciplina na escola, mas que tem um papel de destaque na formação do individuo. A compreensão de escola de tempo integral pressupõe uma educação integral em tempo integral no espaço escolar. Diante do princípio da educação integral, o corpo é fundamental, pois todo o processo formativo é corporal, implicando uma aprendizagem que é corporificada. Para Santin (2001, p. 97):

O corpo humano em movimento é uma riqueza incalculável que pode ser explorada diferentemente pela educação física dependendo da intencionalidade de professores e alunos. O corpo pode ser reduzido a um objeto disciplinado e explorado como um utensílio qualquer, ou pode ser visto como um organismo vivo a ser desenvolvido, vivido e cultuado com equilíbrio e harmonia.

A compreensão de corpo que explicita no currículo da Educação Física implica a ação pedagógica do professor, que também tem suas compreensões de corpo, atribuindo uma identidade ao componente curricular. Essa identidade se modifica, pois "as reformas curriculares estão diretamente vinculadas com a constituição de identidades culturais desejáveis para a consolidação dos interesses em voga" (NUNES; RÚBIO, 2008, p.57). Esses interesses seguem as representações simbólicas do imaginário da sociedade, da escola, dos professores e alunos. Todas essas representações podem sofrer transgressões de cada uma dessas camadas de atores sociais.

A atenção dada ao corpo deve ser atribuída a todas as práticas desenvolvidas na escola, pois “o corpo não é um instrumento das práticas educativas, portanto as produções humanas são possíveis pelo fato de sermos corpo. Ler, escrever, contar, narrar, dançar, jogar são produções do sujeito humano que é corpo" (NÓBREGA, 2005, p. 610).

Ao considerar o corpo em todas as suas dimensões, biológica, social e cultural, temos que vê-lo como expressão de uma cultura de movimento que se constrói na vida do sujeito. Por isso uma educação do/no corpo torna-se fundamental no contexto da escola de tempo integral, consistindo como papel de toda a escola desenvolver uma educação em que o corpo é protagonista, principalmente no atual contexto da sociedade brasileira, onde:

Os corpos infantis-adolescentes sofrem toda precariedade de viver. O ser do corpo, o ser corpóreo está irremediavelmente atrelado ao ser espacial, ao ser temporal, ao 
sermos humanos. Vida-corpo-espaço-tempo são inseparáveis enquanto direitos básicos humanos. (ARROYO, 2012, P. 40).

Podemos reforçar essa ideia de Arroyo (2012) com a perspectiva da pedagogia Freinet, que segundo Dias (2012, p.118) "preconiza a ação e a expressão da criança como suportes de vida, dentro ou fora dos muros escolares". Isso implica pensar que a criança ou jovem utiliza sua expressão como meio de relação com o mundo, pois

Toda forma de expressão coloca o ser no mundo; na expressão corporal, isso não é diferente, pois ela nos favorece compreender de como o ser encontra-se no mundo, no qual a sua leitura desse mesmo mundo, o que lhe desperta e o que aprendeu em nome do seu próprio interesse (DIAS, 2012, p. 128).

Nesse sentido, a Educação Física tem um papel diferencial dos demais componentes curriculares, por ter a possibilidade de desenvolver através da prática pedagógica a consciência corporal por intermédio das manifestações da cultura de movimento que foram constituídas historicamente, além de promover a possibilidade de atribuir novas significações a elas. Isso demanda uma mudança na maneira de pensar a prática pedagógica, ampliando o olhar para uma prática que vai além de seguir instruções de caráter funcionalista, e encarar a realidade de que:

Os conteúdos, as didáticas, as avaliações terão de ser repensados para assegurar o direito primeiro aos educandos de recuperar, ao menos nas salas de aula, seu viver, sua condição corporal, espacial, temporal inseparáveis do direito ao conhecimento, à cultura, aos valores, à formação plena como humanos (ARROYO, 2012, P. 43).

Acreditamos que a formação integral do humano está intrínseca em compreender o sujeito como autor, perpassando pela tomada de consciência das possibilidades do corpo para poder criar seus sentidos numa educação para a liberdade. Nesse sentido, para pensar a prática pedagógica do professor, é importante se atentar para

[...] quatro questões básicas precisam ser respondidas para que as necessidades sejam atendidas: Como estabelecer os objetivos? Quais são os princípios metodológicos de ensino a serem adotados? Como selecionar e estruturar as tarefas de aprendizagem? Como avaliar o progresso de cada aluno? (TANI, 1988, p. 1).

No que se refere aos objetivos, uma prática pedagógica baseada na multirreferencialidade seria desenvolver o sujeito como corpo que existe e compartilha experiências em diversos contextos, criando ambiente de aprendizagem para as práticas corporais, considerando o sujeito em 
sua integralidade. Por exemplo, os jogos podem assumir significados individuais de acordo com o contexto cultural, cabendo ao professor organizar suas aulas de maneira que as experiências dos educandos com relação a determinados jogos sejam consideradas, bem como promover novas possibilidades que amplie a vivências dos mesmos conscientizando sua participação enquanto agente, ator e autor.

Os princípios metodológicos podem variar de acordo com o momento da aula, pois partem do princípio de que os professores podem estar mudando os olhares para o trato dos conteúdos, os quais podem ser selecionados de acordo com a realidade de cada escola, mas que de maneira geral devem ser escolhidos para atender uma demanda local, como uma demanda global.

A avaliação pode ser por diversas ferramentas, que também vão variar de acordo com a referência que o professor esteja utilizando para cada momento. Nesse sentido, o professor pode considerar tanto aspectos objetivos como subjetivo.

Inicialmente é fundamental saber de onde o aluno está partindo no que se refere ao conhecimento abordado, o que implica numa avaliação diagnóstica, nesse aspecto o professor de Educação Física deve considerar as experiências do aluno com a prática corporal abordada enquanto conteúdo, podendo solicitar um relato de experiência, registrar um momento de vivência por vídeo em forma de diário, aplicar um questionário, realizar uma avaliação prática considerando os aspectos motores, entre outras possibilidades.

Logo após a avaliação diagnóstica, deve-se considerar o processo de ensino, momento no qual o professor vai tendo um retorno das estratégias utilizadas, podendo ser através de registros dos próprios alunos através de portfólios e/ou de registros do próprio professor que surgem da observação das vivências ou dos discursos. E como processo avaliativo final é possível retornar a aplicação das avaliações iniciais e realizar comparações tanto por parte do professor, como pelo próprio aluno, realizando autoavaliação.

O professor de Educação Física tem um papel essencial no contexto da escola de tempo integral, pois como diz Nobrega (2005, p. 83-84):

Os profissionais dessa área têm muito a contribuir com a educação, socializando um novo conceito de corpo, a partir das diferentes expressões de movimento que, historicamente, fazem parte do seu acervo e outras, que possam vir a incorporar-se, considerando-se também que o movimento deve despertar no sujeito a percepção de si mesmo como ser corporal, em relação com os outros e com o mundo, e da sensibilidade como atribuidora de significado às ações humanas.

Nas concepções de Educação Física, o corpo se apresenta de alguma maneira, sendo concebido por diversos vieses. Numa perspectiva de Educação Física multirreferencial, o corpo é 
eixo principal, sendo concebido em toda a sua dimensão; na seleção dos conteúdos deve ter "a compreensão de que a produção humana é histórica, inesgotável e provisória" (COLETIVO DE AUTORES, 1992, p. 27) e a prática pedagógica do professor seja por um olhar plural que vislumbre uma educação integral em que os sujeitos participantes do processo educativos se compreendam como coautor de si.

A corporeidade manifestada no corpo do sujeito ocorre através do movimentar-se, é no movimento que o sujeito toma consciência enquanto ser corporal. É através da consciência corporal, entendida com "a percepção que o ser humano possui de sua realidade existencial como corpo em movimento, como corporeidade" (NOBREGA, 2005, p. 80), que a Educação Física pode contribuir para a educação integral do sujeito. Sendo assim, concordamos que

[...] a corporeidade como norte para a ação pedagógica na escola em tempo integral, é pela razão da corporeidade fundamentar-se no corpo em movimento, na configuração de espaço e tempo, tudo isto se relacionando diretamente com a cultura e a história. Desta forma estamos tentando superar a dicotomia entre os conhecimentos racional e sensível (MOREIRA et al, 2014, p. 199).

Partindo da corporeidade, acreditamos que o corpo pode se expressar no mundo de diversas formas a partir do movimento, e que no contexto da educação escolarizada através da Educação Física:

\section{[...] proporciona experiências no mínimo em três áreas:}

Mediante a função instrumental e sensitiva é possível adquirir experiências com o material por meio do movimento.

Por intermédio da função social é possível fazer experiências sociais por meio do contato com outras pessoas.

Por meio da função simbólica é possível fazer experiências corporais mediante um confronto direto como seu próprio corpo pelo movimento (HILDEBRANDETSTRAMANN; TAFFAREL, 2017, p. 39).

Para proporcionar experiências nas áreas relacionadas a funções do movimentar, requer-se do professor de Educação Física se ancorar numa concepção de corpo que o visualize por referências que reconheçam sua totalidade, o que implica um fazer pedagógico de base plural. $\mathrm{Na}$ função instrumental partimos da compreensão de que "o corpo é o primeiro e o mais natural instrumento do homem. Ou, mais exatamente, sem falar de instrumento: o primeiro e o mais natural objeto técnico, e ao mesmo tempo meio técnico, do homem, é seu corpo" (MAUUS, 2003, p.407). Nas aulas de Educação Física, a dimensão prática teve por base o ensino das técnicas do 
movimento, que compreendemos como "um ato tradicional eficaz (e vejam que nisso não difere do ato mágico, religioso, simbólico). Ele precisa ser tradicional e eficaz. Não há técnica e não há transmissão se não houver tradição" (MAUUS, 2003, p.407). Para aprendizagem do movimento, assim como para seu ensino, é preciso reconhecer que existe uma tradição específica de cada cultura, o que era desconsiderado no ensino principalmente do esporte, por se caracterizar por práticas institucionalizadas, e que no processo de globalização universaliza suas práticas. Para Mauss (2003, p. 402):

Outrora nos ensinavam a mergulhar depois de ter aprendido a nadar. E, quando nos ensinavam a mergulhar, nos diziam para fechar os olhos e depois abri-los dentro d'água. Hoje a técnica é inversa. Começa-se toda aprendizagem habituando a criança a ficar dentro d'água de olhos abertos. Assim, antes mesmo que nadem, as crianças são treinadas sobretudo a controlar reflexos perigosos, mas instintivos dos olhos, são antes de tudo familiarizadas com a água, para inibir seus medos, criar uma certa segurança, selecionar paradas e movimentos. Há, portanto, uma técnica do mergulho e uma técnica da educação do mergulho que foram descobertas em meu tempo. E vejam que se trata claramente de um ensino técnico, e que há, como para toda técnica, uma aprendizagem do nado (MAUUS, 2003, p.402).

Essa mudança do ensino da técnica do movimento é algo que tem implicação direta nas maneiras que a Educação Física vai se configurando no espaço escolar enquanto prática cultural. A técnica do movimento sempre esteve presente nas aulas de Educação Física, pois há o uso do corpo. O problema que foi sendo questionado dentro da prática pedagógica eram as estratégias de ensino, que numa perspectiva tradicional não consideravam a subjetividade do aluno na execução do movimento, buscando padrões universalizados, não reconhecendo que "as técnicas corporais só podem ser chamadas técnicas porque são culturais. Não é possível falar de um movimento "não técnico", "natural", "livre", ainda não atingido pela cultura" (DAOLIO, 2013, p. 77).

Essa crítica de tratar o movimento padronizado é apresentada por Freire (1997, p. 24) ao afirmar que "é bem possível que estejamos procurando definir maneiras corretas de movimentação das crianças sem sequer entendê-las como seres que vivem em sociedade num determinado mundo". O movimento está atrelado ao corpo que é definido pelo seu significado, produzido pela cultura e construído em cada sociedade, não pelos fatores biológicos universalizados (DAOLIO, 2013).

O que se torna um equívoco na prática pedagógica com a crítica ao ensino da técnica do movimento é negligenciar o olhar formativo para esse aspecto. O próprio Freire (1997, p. 24) compreende que: 
Em relação ao seu papel pedagógico, a Educação Física deve atuar como qualquer outra disciplina da escola, e não desintegrada dela. As habilidades motoras precisam ser desenvolvidas, sem dúvida, mas deve estar claro quais serão as consequências disso do ponto de vista cognitivo, social e afetivo.

Esse reconhecimento do papel da Educação Física escolar para o desenvolvimento técnico do movimento do educando, não de forma padronizada, é um dos elementos do reconhecimento da identidade do componente curricular na escola, mas repensando

[...] a relação com o outro dessa dinâmica pedagógica, redefinindo-o de forma diferente de outras épocas. Trata-se de definir o outro não mais como objeto de uma intervenção pedagógica pautada pelos parâmetros da aptidão física, sem diluílo em um coletivo abstrato, mas considerá-lo sujeito de uma relação definida pela intersubjetividade (DAOLIO, 2010, p. 17).

Dessa forma, corroboramos a ideia de que:

[...] parece-me necessário negarmos a oposição entre Educação pelo Movimento e Educação do movimento em favor de uma unidade dialética: Educação pelo, do e para o Movimento. A Educação Física possui um conteúdo, um saber, cuja transmissão deve ser assumida como tarefa pela Escola (BRACHT, 1992, p. 29).

O professor de Educação Física tem de assumir que seu componente curricular tem um compromisso com o movimentar-se, e partindo dele ampliar o universo educativo, atendendo uma demanda formativa para as questões da cidadania, ensinar o movimento contextualizando sua presença na humanidade e promover as experiências necessárias para a ampliação das vivências corporais pelas quais o educando possa fazer uso do seu corpo em contextos diversos. Para Nobrega (2005, p. 81):

Não há separação entre a realização mecânica e a significação para o sujeito que se movimenta. Todo movimento é inteligente, possui uma significação. Compreendendo o movimento com esse fio intencional, estaremos superando também o caráter mecanicista e adestrativo dos métodos de ensino enraizados na prática pedagógica da Educação Física.

É importante chamar a atenção para que, ao tratar dessa relação entre diferentes feições da integralidade do ser, o movimento não é ferramenta ou mecanismo para alcançá-las, mas faz parte de uma inter-relação, onde o sujeito as desenvolve em uma troca mútua, na qual o corpo é o centro aglutinador. Compartilhamos a ideia de que: 
No meu entender, este é o sentido mais radical dessas políticas propostas: trazer para a reflexão e a prática pedagógica, didática, docente, curricular gestora a centralidade esquecida do viver, do corpo, dos tempos-espaços nos processos de formação humana, inclusive de educação-aprendizagem-socialização na escola (ARROYO, 2012, P.42).

A escola de tempo integral é constituída por pessoas que são corpos, que se relacionam na dinâmica escolar, cabendo a todos reconhecer a si mesmos e ao outro como corpo adornado de sentidos, que "traz marcas sociais e históricas, portanto questões culturais, questões de gênero, de pertencimentos sociais podem ser lidas no corpo" (NÓBREGA, 2005, p. 610). Dessa forma, a Educação Física tem as práticas corporais como arcabouço de conteúdos e é preciso entender que ela

[...] não é apenas educação do ou pelo movimento: é educação do corpo inteiro, entendendo-se, por isso, um corpo em relação com outros corpos e objetos, no espaço. Educar corporalmente uma pessoa não significa provê-la de movimentos qualitativamente melhores, apenas. Significa também educá-la para não se movimentar, sendo necessário para isso promover-se tensões e relaxamentos, fazer e não-fazer (FREIRE, 1997, p. 84).

O movimentar humano é produzido em tempos e espaços diferentes e vão sendo significados no decorrer da história. Isso atribui a ele uma historicidade que está suscetível a mudanças com o passar do tempo. A presença da Educação Física na escola deve se legitimar por contribuir na formação do educando em sua totalidade, para isso deve olhar para seus conteúdos de maneira mais ampliada, compreendendo-os como partes da cultura de movimento e que requer:

[...] desenvolver uma reflexão pedagógica sobre o acervo de formas de representação do mundo que o homem tem produzido no decorrer da história, exteriorizadas pela expressão corporal: jogos, danças, lutas, exercícios ginásticos, esporte, malabarismo, contorcionismo, mímica e outros, que podem ser identificados como formas de representação simbólica de realidades vividas pelo homem, historicamente criadas e culturalmente desenvolvidas (COLETIVO DE AUTORES, 1992, p. 26).

Pensar o movimento como representações do mundo criadas pela humanidade no decorrer da história é entendê-lo como um conhecimento produzido na ação do sujeito como autor que na relação com o outro passa por metamorfoses que dão origem a novas produções. Sendo assim, como todo conhecimento, ele é transitório e passível de novas representações. Para o Coletivo de Autores (1992), a provisoriedade do conhecimento é um princípio que deve ser observado na 
organização curricular, pois:

A partir dele se organizam e sistematizam os conteúdos de ensino, rompendo com a idéia de terminalidade. É fundamental para o emprego desse princípio apresentar o conteúdo ao aluno, desenvolvendo a noção de historicidade, retraçando-o desde a sua gênese, para que este aluno se perceba enquanto sujeito histórico.

Isso quer dizer que se deve explicar ao aluno que a produção humana, seja intelectual, científica, ética, moral, afetiva etc., expressa um determinado estágio da humanidade e que não foi assim em outros momentos históricos (COLETIVO DE AUTORES, 1992, p.21).

A Educação Física, enquanto prática pedagógica, por muito tempo se justificou pelo referencial da aptidão física e do rendimento com o fim da formação esportiva, privilegiando uma formação voltada para a técnica do movimento padronizado, o que a restringia a um único referencial. Trazer outros pontos de vista para o conteúdo permite que no processo de ensino o professor permita que o

[...] aluno entenda que o homem não nasceu pulando, saltando, arremessando, balançando, jogando etc. Todas essas atividades corporais foram construídas em determinadas épocas históricas, como respostas a determinados estímulos, desafios ou necessidades humanas (COLETIVO DE AUTORES, 1992, p.27).

Para tratar essa dimensão histórica não é possível negar a importância da dialógica no ensino, pois "é necessário que, na situação educativa, educador e educando assumam o papel de sujeitos cognoscentes, mediatizados pelo objeto cognoscível que buscam conhecer" (FREIRE, 1977, p. 28). É nessa relação que a compreensão das práticas que constituem a cultura de movimento vão sendo construídas e recebendo sentidos históricos que atribuem novas significações sociais. Nesse mesmo sentido Kunz (2006, p. 31) diz:

O aluno enquanto sujeito do processo de ensino deve ser capacitado para sua participação na vida social, cultural e esportiva, o que significa não somente a aquisição de uma capacidade de ação funcional, mas a capacidade de conhecer, reconhecer e problematizar sentidos e significados nesta vida, pela reflexão crítica.

A reflexão crítica não pode ser negligenciada nas aulas de Educação Física, pois é a partir dela que o sujeito reconhece o porquê, o como, e onde do fazer, ou seja, compreende a condição do seu corpo no mundo e sua relação com ele. Para Freire (1997, p. 23), "ao descrever qualquer ação, qualquer movimento, não posso deixar de considerar que o ser humano é uma entidade que não se basta por si. Parte do que ele precisa para viver não está nele, mas no mundo fora dele". Esse posicionamento nos mostra a importância de considerar que as relações sociais são fatores 
preponderantes para a organização da prática pedagógica da Educação Física.

\section{CONSIDERAÇÕES FINAIS}

Um dos grandes desafios da escola de tempo integral é ampliar a possibilidade do conhecer, não se restringindo apenas ao depósito de conteúdos pré-estabelecidos, mas um espaço onde a formação humana esteja baseada no vir-a-ser, e o vir-a-seré um processo contínuo, em que todos os conhecimentos da existência nos fazem e refazem.

Para a escola de tempo integral a Educação Física deve ampliar seus referenciais na maneira de conceber o corpo, de compreender a escola, de pensar a aprendizagem e desenvolver a prática pedagógica, pois é preciso refletir sobre seu papel nesse formato escolar, com tempo ampliado e que projeta proporcional educação integral.

É como espaço de relações plurais que concebemos a escola de tempo integral fundamentada na multirreferencialidade, e a Educação Física como parte desse contexto deve desenvolver uma prática pedagógica que perspective uma leitura plural e a consciência corporal dos sujeitos implicados, fazendo-os compreender sua participação na sociedade como agentes, atores e autores que criam sentidos para os usos que fazem do seu corpo. Corpo esse que não é acessório, mas condição existencial do ser que expressa através do movimentar-se.

Uma prática pedagógica baseada nos princípios da multirreferencialidade deve ser concebida como um processo de implicação em que o sujeito educador está em constante troca recíproca com o sujeito educando, compreendendo-se implicado na relação de ensinoaprendizagem.

\section{REFERÊNCIAS}

ARDOINO, Jacques Ardoino. Abordagem multirreferencial (plural) das situações educativas e formativas. In: In: BARBOSA, Joaquim Gonçalves (Coordenador); revisão da tradução Sidney Barbosa. Reflexões em torno da abordagem multirreferencial. - São Carlos: EdUFSCar, 1998.

ARROYO, Miguel G. O direito a tempos-espaços de um justo e digno viver. In: MOLL, Jaqueline (Org.). Caminhos da Educação Integral no Brasil: direito a outros tempos e espaços educativos. Porto Alegre: Penso, 2012.

BARBOSA, Joaquim Gonçalves. Uma escola Multirreferencial: A difícil arte de se autorizar, o pensamento plural de Jacques Ardoino e a Educação. In: Macedo, Roberto Sidnei; Barbosa, Joaquim Gonçalves; BORBA, Sérgio (Orgs). Jacques Ardoino e a Educação. Belo Horizonte: Autêntica Editora, 2012.

BRACHT, Valter. Educação Física e aprendizagem social. Porto Alegre: Magister, 1992. 
COLETIVO DE AUTORES. Metodologia do ensino de educação física. São Paulo: Cortez, 1992.

DAOLIO, Jocimar. A educação física escolar como prática cultural: tensões e riscos. In: DAOLIO, Jocimar (COOR.). Educação física escolar: olhares a partir da cultura. Campinas, SP: Autores Associados, 2010.

DAOLIO, Jocimar. Da cultura do corpo. $17^{\circ}$ ed. Campinas, SP: Papirus, 2013.

DIAS, Maria Aparecida. O corpo na pedagogia Freinet. São Paulo: Editora Livraria da Física, 2012.

FREIRE, João Batista. Educação de corpo inteiro: teoria e prática da educação física. São Paulo: Scipione, 1997.

TANI, Go et al. Educação Física escolar: fundamentos de uma abordagem desenvolvimentista. São Paulo: EPU: Editora da Universidade de São Paulo, 1988.

HILDEBRANDET-STRAMANN, Reiner; TAFFAREL, CeliZulke. Formação de professores e trabalho educativo na educação física. Ijuí: Ed. Unijuí, 2017.

KUNZ, Elenor. Transformação didático-pedagógica do esporte.7. Ed. Ijuí: Ed. Unijuí, 2006.

MAUSS, Marcel. Sociologia e antropologia. São Paulo: Cosac e Naify, 2003.

MELO, José Pereira de. A Educação Física como componente curricular: seu lugar entes os saberes escolares. In: SCHNEIDER, Omar. Et.al (Org). Educação Física, esporte e sociedade: temas emergentes. v, 2. São Cristóvão: Editora da UFS, 2008.

MOREIRA, Wagner Wey, Et al. Educação Integral na escola de tempo integral: fenomenologia, complexidade e corporeidade. In: Simões, Regina; BARBOSA, Juliana Bertucci (Org.). Escola em tempo integral: linguagens e expressões. Uberaba: UFRM, 2014).

NOBREGA, Terezinha Petrucia de. Corporeidade e educação física do corpo-objeto ao corposujeito. 2. ed. Natal, RN: EDUFRN Editora da UFRN, 2005.

NUNES, Mario Luiz Ferrar; RÚBIO, kátia. O(s) currículo(s) da educação física e a constituição da identidade de seus sujeitos. Currículo sem Fronteiras, v.8, n.2, pp.55-77, Jul/Dez 2008.

SANTOS, Antônio de Pádua dos. Imaginário radical e educação física: trajetória esportiva de corredores de longa distância. Natal: EDUFRN, 2012.

SANTIN, Silvino. Educação Física outros caminhos. $2^{\circ}$ ed. Porto Alegre, RS: Edições EST, 1993.

SANTIN, Silvino. Educação Física: temas pedagógicos. $2^{\circ}$ ed. Porto Alegre, RS: Edições EST, 2001.

SAVIANI, Dermeval. Escola e democracia: teorias da educação, curvatura da vara, onze teses sobre educação e política. 32 ed. Campinas, SP: Autores Associados, 1999. 
SOARES, Carmem Lúcia. Prefácio. In: TABORADA DE OLIVEIRA, Marcus Aurelio (org.). Educação do corpo na escola brasileira. Campinas, SP: Autores Associados, 2006.

\section{NOTAS DE AUTOR}

\section{AGRADECIMENTOS}

Agradecemos ao Programa de Pós Graduação em Educação (PPGED) da UFRN, bem como o Grupo de Estudos em Corpo e Cultura de Movimento (GEPEC) do Departamento de Educação Física, pois o presente artigo constitui parte da tese de doutorado do autor principal no PPGED e o GEPEC fez parte desse processo formativo enquanto grupo norteador para as reflexões em torno da pesquisa.

CONTRIBUIÇÃO DE AUTORIA - Não se aplica.

FINANCIAMENTO - Não se aplica.

CONSENTIMENTO DE USO DE IMAGEM - Não se aplica

APROVAÇÃO DE COMITÊ DE ÉTICA EM PESQUISA - Não se aplica.

\section{LICENÇA DE USO}

Os autores cedem à Motrivivência - ISSN 2175-8042 os direitos exclusivos de primeira publicação, com o trabalho simultaneamente licenciado sob a Licença Creative Commons Attribution Non-Comercial ShareAlike (CC BY-NC SA) 4.0 International. Esta licença permite que terceiros remixem, adaptem e criem a partir do trabalho publicado, desde que para fins não comerciais, atribuindo o devido crédito de autoria e publicação inicial neste periódico desde que adotem a mesma licença, compartilhar igual. Os autores têm autorização para assumir contratos adicionais separadamente, para distribuição não exclusiva da versão do trabalho publicada neste periódico (ex.: publicar em repositório institucional, em site pessoal, publicar uma tradução, ou como capítulo de livro), com reconhecimento de autoria e publicação inicial neste periódico, desde que para fins não comerciais e compartilhar com a mesma licença.

\section{PUBLISHER}

Universidade Federal de Santa Catarina. Programa de Pós-Graduação em Educação Física. LaboMídia - Laboratório e Observatório da Mídia Esportiva. Publicado no Portal de Periódicos UFSC. As ideias expressadas neste artigo são de responsabilidade de seus autores, não representando, necessariamente, a opinião dos editores ou da universidade.

\section{EDITORES}

Mauricio Roberto da Silva, Giovani De Lorenzi Pires, Rogério Santos Pereira.

\section{HISTÓRICO}

Recebido em: 02 de abril de 2020.

Aprovado em: 16 de junho de 2020. 